\title{
Cardiovascular Outcomes in Patients with Normal and Abnormal 24-Hour Ambulatory Blood Pressure Monitoring
}

\author{
P. Iqbal and Louise Stevenson \\ Chesterfield Hypertension Clinic, Chesterfield Royal Hospital NHS Foundation Trust, Chesterfield S44 5BL, UK
}

Correspondence should be addressed to P. Iqbal, drpi2pc@aol.com

Received 11 September 2010; Accepted 7 November 2010

Academic Editor: Samy I. McFarlane

Copyright (๑) 2011 P. Iqbal and L. Stevenson. This is an open access article distributed under the Creative Commons Attribution License, which permits unrestricted use, distribution, and reproduction in any medium, provided the original work is properly cited.

\begin{abstract}
Introduction. 24-hour ambulatory blood pressure monitoring (ABPM) plays an important role in assessing cardiovascular prognosis, through presence or absence of ABPM-related prognostic features. Objectives. To study relationship between 24-hour ABPM and cardiovascular outcomes in patients from Chesterfield Royal Hospital. Material and Methods. Over 12 months from the 1st of August 2002, 1187 individuals had 24-hour ABPM performed. Cardiovascular outcomes were studied in a subset (297) of the original cohort, made up by every 4th consecutive subject. The following ABPM-related prognostic features were studied-high day time systolic and diastolic BP $(\geq 135, \geq 85 \mathrm{mmHg})$, high night time systolic and diastolic BP $(\geq 120 \mathrm{mmHg}$, $\geq 75 \mathrm{mmHg}$ ), absence of nocturnal dip ( $\leq 10 \%$ fall in night time SBP), high early morning SBP ( $\geq 140 \mathrm{mmHg}$ ), and morning surge $(\geq 20 / 15 \mathrm{mmHg}$ ). The cardiovascular outcomes studied in the fourth table included fatal and nonfatal MI, new diagnosis of angina, acute coronary syndrome, sudden cardiac death, cardiac arrhythmias, acute LVF, cerbrovascular events, peripheral vascular disease, abdominal aortic aneurysm, and CKD stage 3 or above. Results. Over a followup period of $2015 \pm 116$ days (1720-2305 days) 82 cardiovascular events occurred in 61 subjects. Cardiac arrhythmias were the most common CV outcome (34 events) followed by cerebrovascular events (15). Statistically significant associations found were between cerebrovascular events and absent nocturnal $\operatorname{dip} \leq 10 \%(P=.05)$ and high day time DBP $(P=.029)$, peripheral vascular disease and morning surge $\geq 20 / 15 \mathrm{mmHg}(P=.014)$, cardiac arrhythmias and high day time and night time DBP $(P=.009$ and .033 , resp. $)$. Conclusion. Significant associations were found between cerebrovascular events and absent nocturnal dip $\leq 10 \%$ and high day time DBP, peripheral vascular disease and morning surge $\geq 20 / 15 \mathrm{mmHg}$, cardiac arrhythmias and high day time and night time DBP.
\end{abstract}

\section{Introduction}

24-hour ABPM plays an important role in determining cardiovascular prognosis and has been shown to be a better predictor of cardiovascular morbidity and mortality as compared to office blood pressure measurements [1-3].

\section{Objectives}

The objective was to study the relationship between $24 \mathrm{H}$ ABPM and cardiovascular outcomes in patients from Chesterfield Royal hospital. It was a retrospective observational study based on review of clinical case notes.

\section{Material and Methods}

Over 12 months from the 1st of August 2002, 1187 individuals had 24-hour ABPM performed. These individuals represented a typical spectrum of patients attending for $24 \mathrm{H}$ ABPM with blood pressure at different stages and with varying durations of hypertension. Cardiovascular outcomes were studied in a subset (297) of the original cohort, made up by every 4 th consecutive subject.

The inclusion criteria were as follows.

(i) Individuals must have one of the recognized indications for 24-hour ABPM, as outlined in Table 1. 


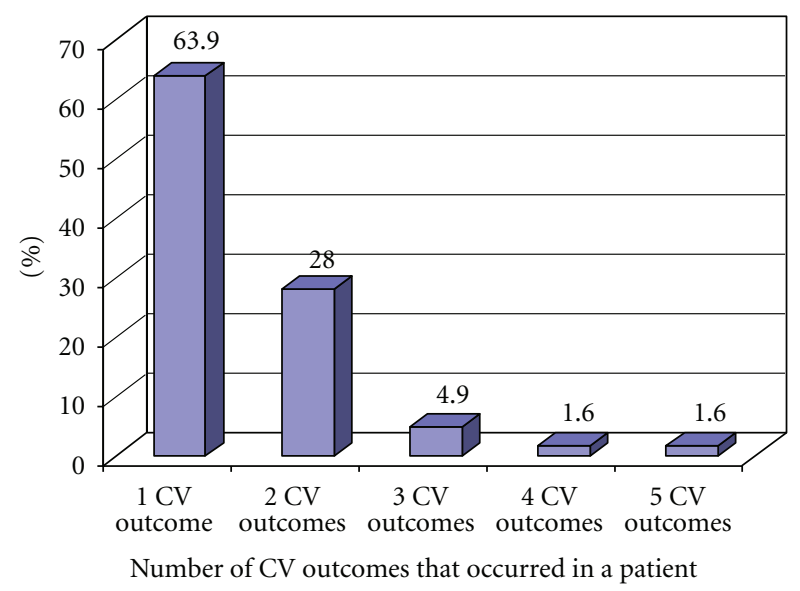

Figure 1: Distribution of number of CV outcomes in 61 patients.

(ii) Every 4th consecutive patient was entered into the study, giving a total of 297, patients. Table 2 outlines demographics and blood pressure criteria between the original cohort and the study cohort.

The exclusion criteria were as follows.

(i) Clinical case notes to study prognostic information were not available from 52 subjects and they were excluded leaving 245 patients.

The following ABPM-related prognostic features were studied (Table 3) high day time systolic and diastolic BP $(\geq 135, \geq 85 \mathrm{mmHg})$, high night time systolic and diastolic BP ( $\geq 120 \mathrm{mmHg}, \geq 75 \mathrm{mmHg}$ ), absence of nocturnal dip $(\leq 10 \%$ fall in night time SBP), high early morning SBP $(\geq 140 \mathrm{mmHg})$, and morning surge $(\geq 20 / 15 \mathrm{mmHg}$ rise in the first two morning readings from $7 \mathrm{AM}$ as compared to average night time BP) [4]. The cardiovascular outcomes studied (Table 4) included fatal and nonfatal MI, new diagnosis of angina, acute coronary syndrome, sudden cardiac death, cardiac arrhythmias, acute LVF, cerebrovascular events, peripheral vascular disease, abdominal aortic aneurysm, and CKD stage 3 or above.

\section{Results}

Over a followup period of $2015 \pm 116$ days (1720-2305 days) 82 cardiovascular events occurred in 61 subjects. Cardiac arrhythmias were the most common CV outcome (34 events) followed by cerebrovascular events (15). Statistically significant associations found were between cerebrovascular events and absent nocturnal dip $\leq 10 \%(P=.05)$ and high day time DBP $(P=.029)$, peripheral vascular disease and morning surge $\geq 20 / 15 \mathrm{mmHg}(P=.014)$, cardiac arrhythmias and high day time and night time DBP $(P=$ .009 and, 033, resp.). Age and gender did not have any statistical associations with the outcomes.
TABle 1

\begin{tabular}{l}
\hline Indications for 24-hour ABPM \\
\hline Borderline hypertension \\
Variable clinic blood pressure \\
Suspected white coat hypertension \\
Suspected white coat effect \\
Resistant hypertension \\
Hypertension in pregnancy \\
Hypertension in elderly patients \\
Evaluation of symptoms suggesting postural hypotension \\
Evaluation of symptomssuggesting drug induced hypotension \\
Blood pressure evaluation in patients with the suspected or \\
proven autonomic dysfunction \\
As an overall guide to hypertension treatment \\
As a prognostic cardiovascular tool
\end{tabular}

\section{Discussion}

In this study, cardiac arrhythmias were the most commonly observed event accounting for $13.9 \%$ of the total events. Atrial fibrillation was the most common cardiac arrhythmia seen in $14 / 38$ (52.9\%) patients with cardiac arrhythmias, followed by symptomatic ventricular ectopics in 13 subjects $(38.2 \%)$ and supraventricular tachycardia and sinoatrial pause in 1 patient each.

Atrial fibrillation is being recognised as a common problem in patients with hypertension. It has been shown to be associated with systolic hypertension [4] and high pulse pressure [5]. Atrial fibrillation may complicate even mildly raised blood pressure, and it would be reasonable to assume that there is no threshold below which the risk of atrial fibrillation is not increased [6]. To the best of our knowledge, our study is the first one to show an increased risk of atrial fibrillation with high day time and night time diastolic blood pressure. Having said that, one of the recent Japanese studies has shown that control of both systolic and diastolic blood pressure is important in reducing risk of new onset atrial fibrillation [7]. 
TABLE 2: Comparison of cohorts 1 and 2.

\begin{tabular}{|c|c|c|c|c|c|}
\hline \multirow{3}{*}{ Age } & \multicolumn{2}{|c|}{ Cohort 1: 1187 patients } & \multicolumn{2}{|c|}{ Cohort 2: 245 patients } & \multirow{2}{*}{$\begin{array}{c}\text { Statistical significance } \\
\text { NS }\end{array}$} \\
\hline & & & & & \\
\hline & $N$ & $\%$ & $N$ & $\%$ & \\
\hline Male & 547 & 46.1 & 107 & 43.7 & NS \\
\hline Female & 640 & 53.9 & 138 & 56.3 & \\
\hline Adverse features & $N$ & $\%$ & $N$ & $\%$ & \\
\hline High $P P \geq 50 \mathrm{mmHg}$ & 736 & 62.0 & 161 & 65.7 & NS \\
\hline High DSBP $\geq 135 \mathrm{mmHg}$ & 703 & 59.2 & 146 & 59.6 & NS \\
\hline High DDBP $\geq 85 \mathrm{mmHg}$ & 515 & 43.4 & 101 & 41.2 & NS \\
\hline High NSBP $\geq 120 \mathrm{mmHg}$ & 639 & 54.0 & 138 & 56.3 & NS \\
\hline High NDBP $\geq 75 \mathrm{mmHg}$ & 404 & 34.0 & 83 & 33.9 & NS \\
\hline Absent ND $\leq 10 \%$ & 677 & 57.0 & 134 & 54.7 & NS \\
\hline High EM SBP $\geq 140 \mathrm{mmHg}$ & 396 & 33.4 & 74 & 30.2 & NS \\
\hline High $\mathrm{MS} \geq 20 / 15 \mathrm{mmHg}$ & 552 & 46.5 & 106 & 43.3 & NS \\
\hline No. adverse features & $N$ & $\%$ & $N$ & $\%$ & NS \\
\hline 0 & 63 & 5.3 & 13 & 5.3 & NS \\
\hline 1 & 114 & 9.6 & 22 & 9.0 & NS \\
\hline 2 & 177 & 14.9 & 35 & 14.3 & NS \\
\hline 3 & 168 & 14.2 & 43 & 17.6 & NS \\
\hline 4 & 176 & 14.8 & 35 & 14.3 & NS \\
\hline 5 & 182 & 15.3 & 37 & 15.1 & NS \\
\hline 6 & 151 & 12.7 & 30 & 12.2 & NS \\
\hline 7 & 119 & 10.0 & 23 & 9.4 & NS \\
\hline 8 & 37 & 3.1 & 7 & 2.9 & NS \\
\hline Adverse Features groups & $N$ & $\%$ & $N$ & $\%$ & \\
\hline $0-2$ & 354 & 29.8 & 70 & 28.6 & \\
\hline $3-5$ & 526 & 44.3 & 115 & 46.9 & NS \\
\hline $6-8$ & 307 & 25.9 & 60 & 24.5 & \\
\hline
\end{tabular}

There was no significant difference between the two cohorts.

(Oneway Anova was used for comparing cohort 1 and 2 ages; cross-tabulation with chi-square Test was used to compare adverse features; no. of adverse features and adverse features groups and gender).

TABLE 3: List of adverse prognostic features noted on 24-hour ABPM.

\begin{tabular}{lc}
\hline Adverse features & Values* \\
\hline High pulse pressure & $\geq 50 \mathrm{mmHg}$ \\
High day systolic BP & $\geq 135 \mathrm{mmHg}$ \\
High day diastolic BP & $\geq 85 \mathrm{mmHg}$ \\
High night systolic BP & $\geq 120 \mathrm{mmHg}$ \\
High night diastolic BP & $\geq 75 \mathrm{mmHg}$ \\
Absent nocturnal dip & $\leq 10 \%$ \\
High early morning systolic BP & $\geq 140 \mathrm{mmHg}$ \\
High morning surge & $\geq 20 / 15 \mathrm{mmHg}$ \\
\hline
\end{tabular}

*K. Madin and P. Iqbal (PMJ 2006)

Over the years a variety of other risk factors for atrial fibrillation have been identified such as large left-atrial size, obesity, thyrotoxicosis, and high alcohol. Our study does not take into account these risks factors.

The exact mechanism for atrial fibrillation in hypertensive subjects is not understood but is believed to be related to left ventricular hypertrophy and an increase in left-atrial size [8], left-atrial fibrosis secondary to high systolic blood pressure [9] and changes in autonomic tone with higher intreatment heart rate on serial ECGs [10].

Atrial fibrillation is an important cardiovascular risk factor for thromboembolic cardiovascular disease and adds to the existing risk from hypertension itself. Treatment of hypertension exclusively with ACE inhibitors, angiotensinII-receptor blockers, and beta blockers was shown to be associated with a lower risk of developing atrial fibrillation than current exclusive therapy with calcium-channel blockers [11].

In summary, our study shows that diastolic hypertension plays an important role in leading to cardiac arrhythmias, in particular atrial fibrillation, and should be treated as vigorously as systolic hypertension.

The study's main limitation is that it did not take into account presence or absence of other cardiovascular risk factors, such as diabetes mellitus, smoking, hyperlipidaemia, or family history, and has relied entirely on blood pressure criterias. The authors would like to acknowledge that this may have had bearing on some of the findings. 
TABLE 4

\begin{tabular}{l}
\hline List of CV outcomes, detected on retrospective case notes review. \\
\hline Non-fatal ST segment elevated MI (ESC/ACC 2000) \\
Non-fatal non-ST segment elevated MI (ACC/AHA2007) \\
Non-fatal acute coronary syndrome \\
New diagnosis of angina pectoris (typical history and positive treadmill cardiac test) \\
Fatal ST segment elevated MI (ESC/ACC 2000) \\
Fatal non-ST segment elevated MI \\
Fatal acute coronary syndrome \\
Sudden cardiac death (ACC/AHA 2006) \\
Cardiac arrhythmias (resting or ambulatory ECG documented evidence of any supraventricular and ventricular arrhythmias) \\
Acute left ventricular failure (typical clinical history backed by chest X-ray finding) \\
Fatal or non-fatal cerebrovascular event (typical clinical history and CT/MRI findings) \\
Renal failure (CKD stage 3 or above, developing during the followup period, according to K/DOQI 2002) \\
Peripheral vascular disease, typical symptoms supported by bilateral lower limb arterial Doppler \\
Fatal or non-fatal abdominal aortic aneurysm $\geq 4$ cm on abdominal ultrasound done in the followup period \\
\hline
\end{tabular}

TABLE 5

\begin{tabular}{|c|c|}
\hline $\begin{array}{l}\text { 82-Cardiovascular outcomes in } 61 \\
\text { patients }\end{array}$ & Frequency \\
\hline Myocardial infarction & $6(2.4 \%)$ \\
\hline Acute coronary syndrome & $3(1.2 \%)$ \\
\hline New diagnosis of angina pectoris & $4(1.6)$ \\
\hline Sudden cardiac death & 0 \\
\hline Cardiac arrhythmias & $34(13.9 \%)$ \\
\hline Acute left ventricular failure & 0 \\
\hline $\begin{array}{l}\text { Fatal or non-fatal cerebrovascular } \\
\text { event }\end{array}$ & $15(6.5 \%)$ \\
\hline Peripheral vascular disease & $5(2 \%)$ \\
\hline $\begin{array}{l}\text { Fatal or non-fatal abdominal aortic } \\
\text { aneurysm }\end{array}$ & $1(0.4 \%)$ \\
\hline Renal failure (CKD $\geq$ stage 3$)$ & $14(5.7 \%)$ \\
\hline \multicolumn{2}{|l|}{$\begin{array}{l}\text { Statistically significant associations } \\
\text { (Fisher exact test) }\end{array}$} \\
\hline $\begin{array}{l}\text { Cerebrovascular events and absent } \\
\text { nocturnal dip } \leq 10 \%\end{array}$ & $P=.50$ \\
\hline $\begin{array}{l}\text { Cerebrovascular events high day time } \\
\text { DBP }\end{array}$ & $P=.029$ \\
\hline $\begin{array}{l}\text { Peripheral vascular disease and } \\
\text { morning surge } \geq 20 / 15 \mathrm{mmHg}\end{array}$ & $P=.014$ \\
\hline $\begin{array}{l}\text { Cardiac arrhythmias and high day } \\
\text { time }\end{array}$ & $P=.009$ \\
\hline $\begin{array}{l}\text { Cardiac arrhythmias and night time } \\
\text { DBP }\end{array}$ & $P=.033$ \\
\hline
\end{tabular}

\section{References}

[1] E. Dolan, A. Stanton, L. Thijs et al., "Superiority of ambulatory over clinic blood pressure measurement in predicting mortality: the Dublin outcome study," Hypertension, vol. 46, no. 1, pp. 156-161, 2005.

[2] K. Eguchi, T. G. Pickering, S. Hoshide et al., "Ambulatory blood pressure is a better marker than clinic blood pressure in predicting cardiovascular events in patients with/without type
2 diabetes," American Journal of Hypertension, vol. 21, no. 4, pp. 443-450, 2008.

[3] E. Dolan, A. V. Stanton, S. Thom et al., "Ambulatory blood pressure monitoring predicts cardiovascular events in treated hypertensive patients-an Anglo-Scandinavian cardiac outcomes trial sub-study," Journal of Hypertension, vol. 27, no. 4, pp. 876-885, 2009.

[4] B. M. Psaty, T. A. Manolio, L. H. Kuller et al., "Incidence of and risk factors for atrial fibrillation in older adults," Circulation, vol. 96, no. 7, pp. 2455-2461, 1997.

[5] G. F. Mitchell, R. S. Vasan, M. J. Keyes et al., "Pulse pressure and risk of new-onset atrial fibrillation," Journal of the American Medical Association, vol. 297, no. 7, pp. 709-715, 2007.

[6] D. Conen, U. B. Tedrow, B. A. Koplan, R. J. Glynn, J. E. Buring, and C. M. Albert, "Influence of systolic and diastolic blood pressure on the risk of incident atrial ribrillation in women," Circulation, vol. 119, no. 16, pp. 2146-2152, 2009.

[7] Y. Tanabe, Y. Kawamura, N. Sakamoto, N. Sato, K. Kikuchi, and N. Hasebe, "Blood pressure control and the reduction of left atrial overload is essential for controlling atrial fibrillation," International Heart Journal, vol. 50, no. 4, pp. 445-456, 2009.

[8] S. M. Vaziri, M. G. Larson, E. J. Benjamin, and D. Levy, "Echocardiographic predictors of nonrheumatic atrial fibrillation: the Framingham Heart Study," Circulation, vol. 89, no. 2, pp. 724-730, 1994.

[9] T. M. Seccia, A. S. Belloni, R. Kreutz et al., "Cardiac fibrosis occurs early and involves endothelin and AT-1 receptors in hypertension due to endogenous angiotensin II," Journal of the American College of Cardiology, vol. 41, no. 4, pp. 666-673, 2003.

[10] P. M. Okin, K. Wachtell, S. E. Kjeldsen et al., "Incidence of atrial fibrillation in relation to changing heart rate over time in hypertensive patients: the LIFE study," Circulation. Arrhythmia and electrophysiology, vol. 1, no. 5, pp. 337-343, 2008.

[11] B. A. Schaer, C. Schneider, S. S. Jick, D. Conen, S. Osswald, and C. R. Meier, "Risk for incident atrial fibrillation in patients who receive antihypertensive drugs: a nested case-control study," Annals of Internal Medicine, vol. 152, no. 2, pp. 78-84, 2010 . 


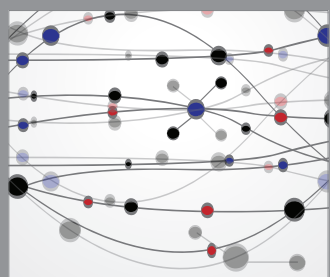

The Scientific World Journal
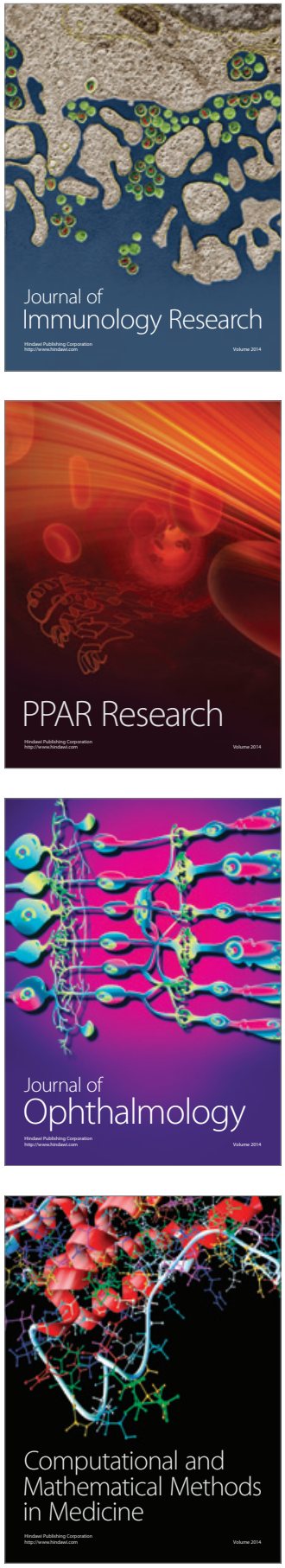

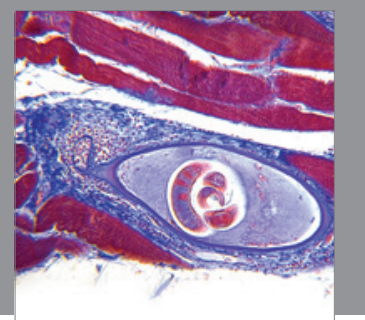

Gastroenterology

Research and Practice
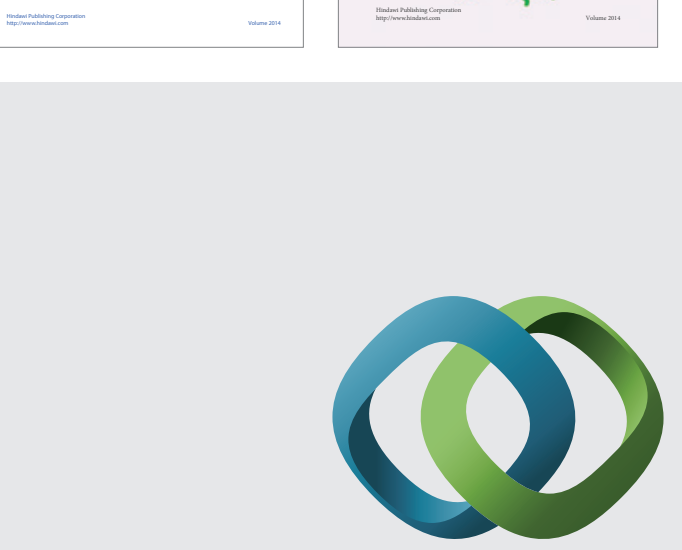

\section{Hindawi}

Submit your manuscripts at

http://www.hindawi.com
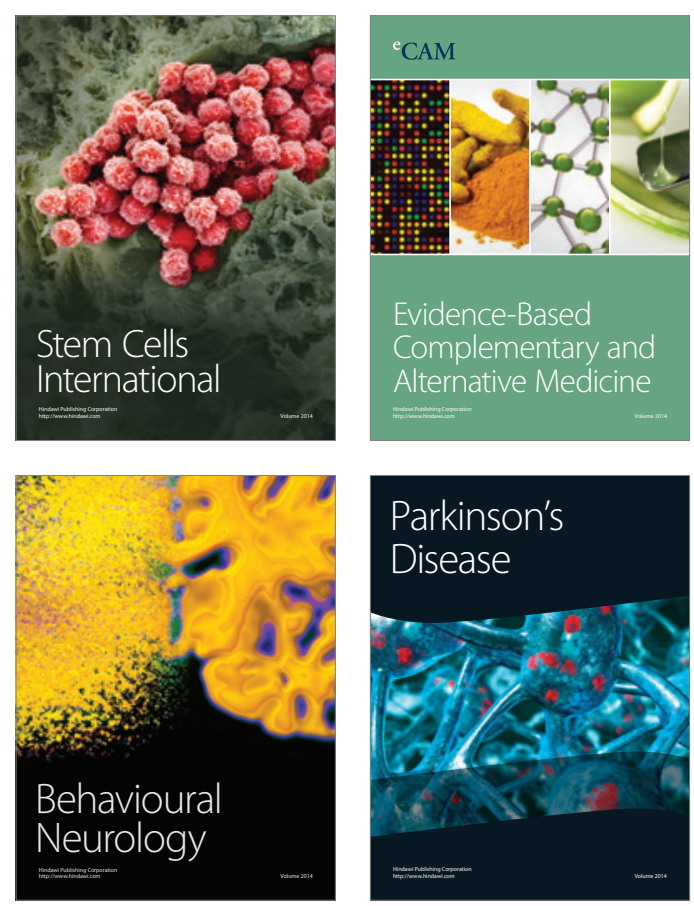

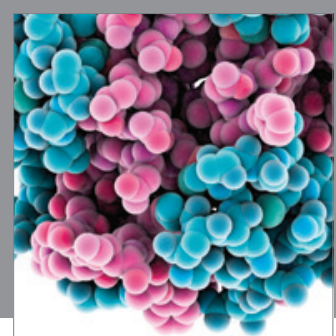

Journal of
Diabetes Research

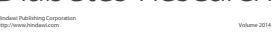

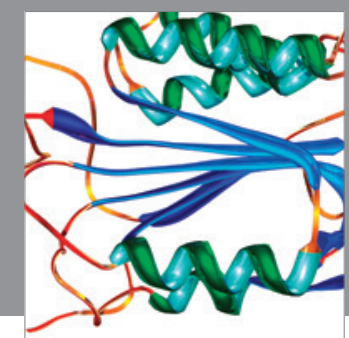

Disease Markers
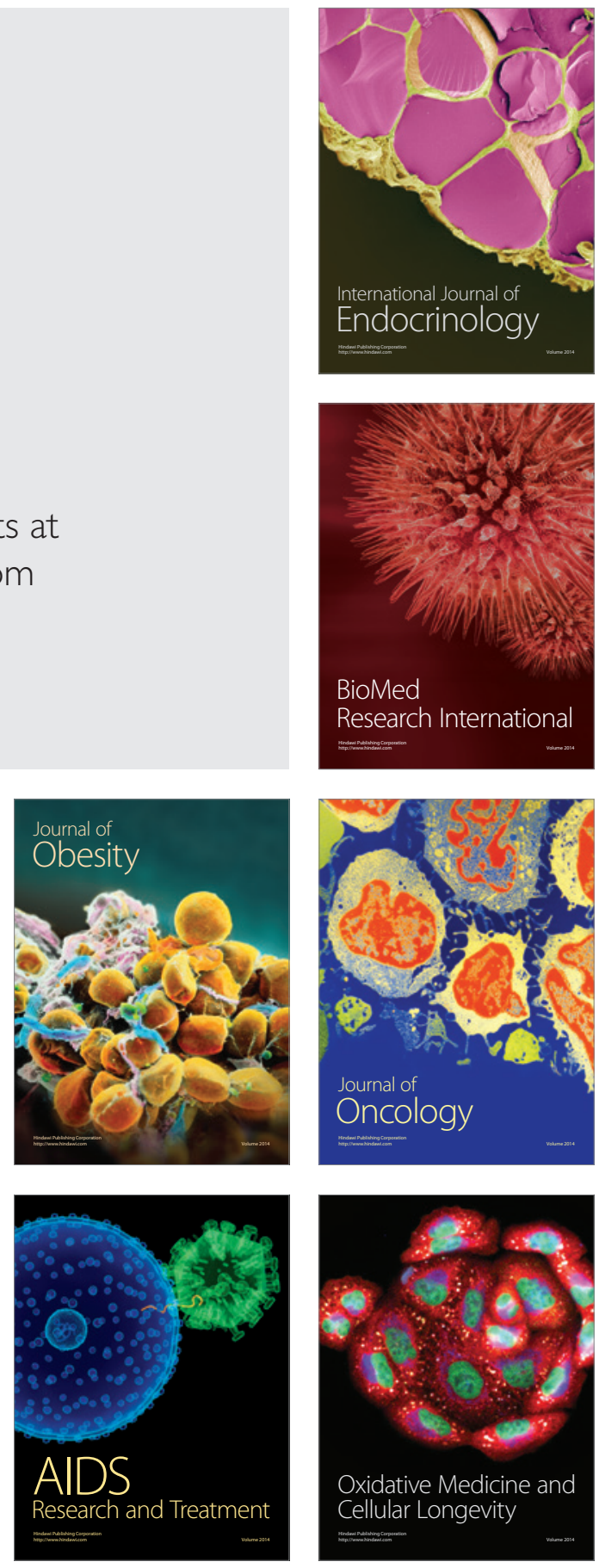